\title{
PENGEMBANGAN INSTRUMEN TES KETERAMPILAN PROSES SAINS PADA MATERI FISIKA UNTUK SISWA SEKOLAH MENENGAH PERTAMA
}

\author{
Nurhayati $^{1}$, Dwi Fajar Saputri ${ }^{2}$, Syarif Lukman Hakim Assegaf ${ }^{3}$ \\ ${ }^{1,2,3}$ Program Studi Pendidikan Fisika, Fakultas Pendidikan MIPA dan Teknologi \\ IKIP PGRI Pontianak, Jalan Ampera Nomor 88 Pontianak - 78116 \\ 1email: nurhayatideli@gmail.com
}

\begin{abstract}
Abstrak
Penelitian bertujuan untuk menghasilkan perangkat instrumen penilaian untuk mengukur keterampilan proses sains pada materi optika, tekanan, dan getaran gelombang. Penelitian merupakan penelitian research and development dengan tahapan 4D yang dibatasi hanya menggunakan tiga tahapan yaitu tahap define, design, dan development. Instrumen penelitian berupa angket uji kelayakan soal yang ditujukan kepada validator dan angket respons siswa. Subjek penelitian adalah siswa kelas IX SMP Negeri yang ada di Kecamatan Sungai Kakap yang berjumlah 20 orang. Tes yang dikembangkan berbentuk pilihan ganda beralasan dan essay. Hasil penelitian menunjukkan bahwa: (1) Validitas atau kelayakan instrumen KPS yang dikembangkan berdasarkan pakar adalah valid dan layak digunakan; (2) Validitas butir soal instrumen penilaian KPS yang dikembangkan dengan kriteria valid; (3) Reliabilitas soal dari instrumen KPS sangat kuat untuk soal pilihan ganda materi optika dan getaran gelombang; reliabilitas kuat untuk soal materi tekanan; dan reliabilitas sedang untuk soal essay materi optika, tekanan, dan getaran gelombang; dan (4) Soal-soal yang dikembangkan dalam instrumen penilaian KPS didominasi soal dengan tingkat kesukaran kategori sedang.
\end{abstract}

Kata Kunci: keterampilan proses sains, optika, tekanan, getaran dan gelombang.

\begin{abstract}
The research aims to produce an instrument of assessment to measure science process skills in optical material, pressure and vibration waves. This research is a research and development study with $4 D$ stages that are limited to only using three stages, namely the define, design, and development stages. The research instrument was in the form of questionnaire due diligence questions addressed to students' validators and questionnaires. The subjects were grade IX students of one of the 20 state junior high schools in Sungai Kakap. The developed test is in the form of multiple-choice reasoning and essay. The results of the study show that: (1) The validity or feasibility of the developed KPS instrument is valid and suitable for use; (2) The validity of items from the KPS assessment instruments developed with valid criteria; (3) The reliability of the questions from the KPS instrument is very strong for the matter of multiple-choice optical material and wave vibrations; strong reliability for matter of pressure material; and moderate reliability for optical material, pressure, and wave vibration essays; and (4) Questions developed in the KPS assessment instrument are dominated by problems with difficulty level medium category.
\end{abstract}

Keywords: science process skills, optics, pressure, vibration and waves. 


\section{PENDAHULUAN}

Kurikulum 2013 mengutamakan pembelajaran yang diarahkan untuk dapat mengembangkan hard skill dan soft skill siswa dengan penguasaan kompetensi meliputi ranah kognitif, afektif, dan psikomotorik. Berdasarkan lampiran Permendikbud Nomor 66 Tahun 2013 tentang Standar Penilaian Pendidikan, penilaian pendidikan merupakan proses pengumpulan dan pengolahan informasi untuk mengukur pencapaian hasil belajar peserta didik yang meliputi pengetahuan, keterampilan, dan sikap. Mengacu pada dua hal tersebut, maka seorang guru diarahkan untuk merancang pembelajaran yang dapat mengembangkan kemampuan berpikir siswa dan penilaian yang dilakukannya juga menekankan kompetensi hard skill maupun soft skill.

Menurut Arifin, dkk. (2016), penilaian atau assesment merupakan suatu proses atau kegiatan yang sistematis dan berkesinambungan untuk mengumpulkan informasi tentang proses dan hasil belajar peserta didik dalam rangka membuat keputusan-keputusan berdasarkan kriteria dan pertimbangan tertentu. Menurut Jihad dan Haris (2012), penilaian berfungsi sebagai pemantau kinerja komponenkomponen kegiatan proses belajar-mengajar dalam mencapai tujuan yang diharapkan dan dikembangan berdasarkan prinsip menyeluruh, berkelanjutan, berorientasi pada indikator ketercapaian, dan sesuai dengan pengalaman. Salah satu prinsipnya yaitu berorientasi pada indikator ketercapaian yang sudah ditetapkan berdasarkan kemampuan dasar dan standar kompetensinya. Artinya penilaian yang dilakukan disesuaikan dengan pendekatan apa yang digunakan dalam pembelajaran.

Berdasarkan hasil observasi yang dilakukan di salah satu SMP Negeri yang ada di Kecamatan Sungai Kakap diketahui bahwa pembelajaran yang dilakukan guru telah inovatif dikarenakan guru sudah menerapkan model yang berbasis pendekatan saintifik, yaitu proses pembelajaran yang meminta siswa untuk mengamati, menjelaskan, dan membuat kesimpulan berdasarkan apa yang siswa amati. Akan tetapi, ketika dilihat instrumen penilaian yang digunakan guru masih mengukur kognitifnya saja. Padahal, proses pembelajaran dengan langkahlangkah saintifik dapat melatih keterampilan proses sains (KPS) siswa. KPS 
terdiri dari observasi, klasifikasi, pengukuran, pengaturan korelasi angka dan ruang, memprediksi, mengatur data, merumuskan model, menafsirkan, mengidentifikasi variabel, merumuskan hipotesis dan akhirnya bereksperimen (Feyzioglu, 2009).

Menurut Harlen (Apriyani, 2017), KPS perlu dilatihkan agar siswa dapat mendefinisikan masalah yang ada di sekitar, mengamati, menganalisis, bereksperimen, menyimpulkan, menggeneralisasi, dan menghubungkan informasi yang siswa miliki dengan keterampilan yang diperlukan. Tujuan pembelajaran sebaiknya diarahkan untuk melatih KPS siswa sehingga kegiatan pembelajaran harus menggunakan model yang dapat mendukung dilatihkannya KPS, begitu juga dengan penilaian (Zamista dan Kaniawati, 2015). Oleh karenanya, harus ada penilaian khusus yang digunakan untuk mengukur KPS siswa. Hasil penelitian Wati, dkk. (2015) menunjukkan bahwa KPS siswa di Indonesia masih relatif rendah, salah satu faktor penyebabnya adalah penilaian yang digunakan cenderung hanya menilai kemampuan kognitif saja. Okaviani, dkk. (2015) mengemukakan bahwa banyak guru yang mengetahui tentang KPS tetapi tidak paham, sehingga tidak menerapkannya dalam proses pembelajaran maupun evaluasinya. Hal yang sama yang ditemukan di salah satu SMP Negeri yang ada di Sungai Kakap, berdasarkan hasil wawancara diketahui bahwa guru telah memahami tentang KPS, akan tetapi alat evaluasi yang digunakan hanya mengukur kemampuan kognitif saja.

Kondisi tersebut belum sesuai dengan kurikulum 2013, bahwa yang perlu dinilai adalah kemampuan soft skill, salah satunya yaitu KPS yang diangkat sebagai bentuk keterampilan yang perlu dikembangkan, digunakan, dan diukur ketercapaiannya. Oleh karenanya, perlu ada instrumen tes yang dibuat untuk mengukur KPS siswa. Sehingga berdasarkan permasalahan tersebut, maka dilakukan penelitian dengan mengembangkan instrumen tes yang dapat mengukur KPS siswa pada materi fisika.

Menurut Rustaman (2005) terdapat enam langkah dalam penyusunan butir soal keterampilan proses yang mengharuskan penguasaan masing-masing jenis keterampilan prosesnya, yaitu: (1) Mempersiapkan pertanyaan atau perintah yang 
dimaksudkan untuk memperoleh respons atau jawaban yang diharapkan; (2) Menentukan bagaimana bentuk respons yang diminta, seperti memberi tanda silang pada huruf a/b/c atau memberi tanda cek pada kolom yang sesuai atau menuliskan jawaban singkat atau bentuk lainnya; (3) Butir keterampilan proses sains tidak boleh dibebani konsep. Artinya konsep yang digunakan harus diyakini oleh penyusun pokok uji sudah dipelajari siswa atau tidak asing bagi siswa; (4) Butir soal KPS mengandung sejumlah informasi berupa gambar, diagram, grafik, data dalam tabel atau uraian atau objek aslinya yang harus diolah oleh responsden atau siswa; (5) Aspek yang akan diukur oleh butir soal keterampilan proses sains harus jelas dan hanya mengandung satu aspek saja, misalnya aspek mengamati; dan (6) Sebaiknya ditampilkan gambar untuk membantu menghadirkan objek, menganalisis penyelidikian, menyusun hipotesis, menentukan variabel secara operasional, merencanakan penyelidikan, dan melalukan eksperimen.

\section{METODE}

Metode penelitian yang digunakan adalah metode penelitian dan pengembangan atau Research and Development (R\&D). Produk yang dikembangkan yaitu instrumen tes KPS untuk mengukur KPS siswa SMP pada materi tekanan, getaran dan gelombang, dan optika. Model pengembangan yang digunakan yaitu model pengembangan 4D (four D model) oleh Thigarajan, dkk. (1974). Model pengembangan 4D terdiri atas 4 tahap utama yaitu Define (Pendefinisian), Design (Perancangan), Develop (Pengembangan), dan Disseminate (Penyebaran).

Tahap define memiliki tujuan untuk mengumpulkan informasi-informasi yang berkaitan dengan penelitian yang dilakukan. Informasi tersebut dapat berasal dari studi literatur maupun studi lapangan. Tahap design memiliki tujuan untuk mendesain instrumen-instrumen yang diperlukan selama penelitian dan mendesain rancangan produk yang hendak dikembangkan. Tahap develop memiliki tujuan untuk mengembangkan produk yang telah dirancang agar menjadi produk yang layak untuk diimplementasikan. Tahap disseminate memiliki tujuan untuk 
menyebarluaskan dan menyosialisasikan produk akhir yang telah dikembangkan secara global.

Tahapan yang dilakukan dalam penelitian hanya sampai pada tahap develop, yaitu tahap revisi hasil uji coba produk setelah tahap uji coba awal secara terbatas. Adapun langkah-langkah pengembangan yang dilakukan dalam penelitian disajikan pada Gambar 1 .

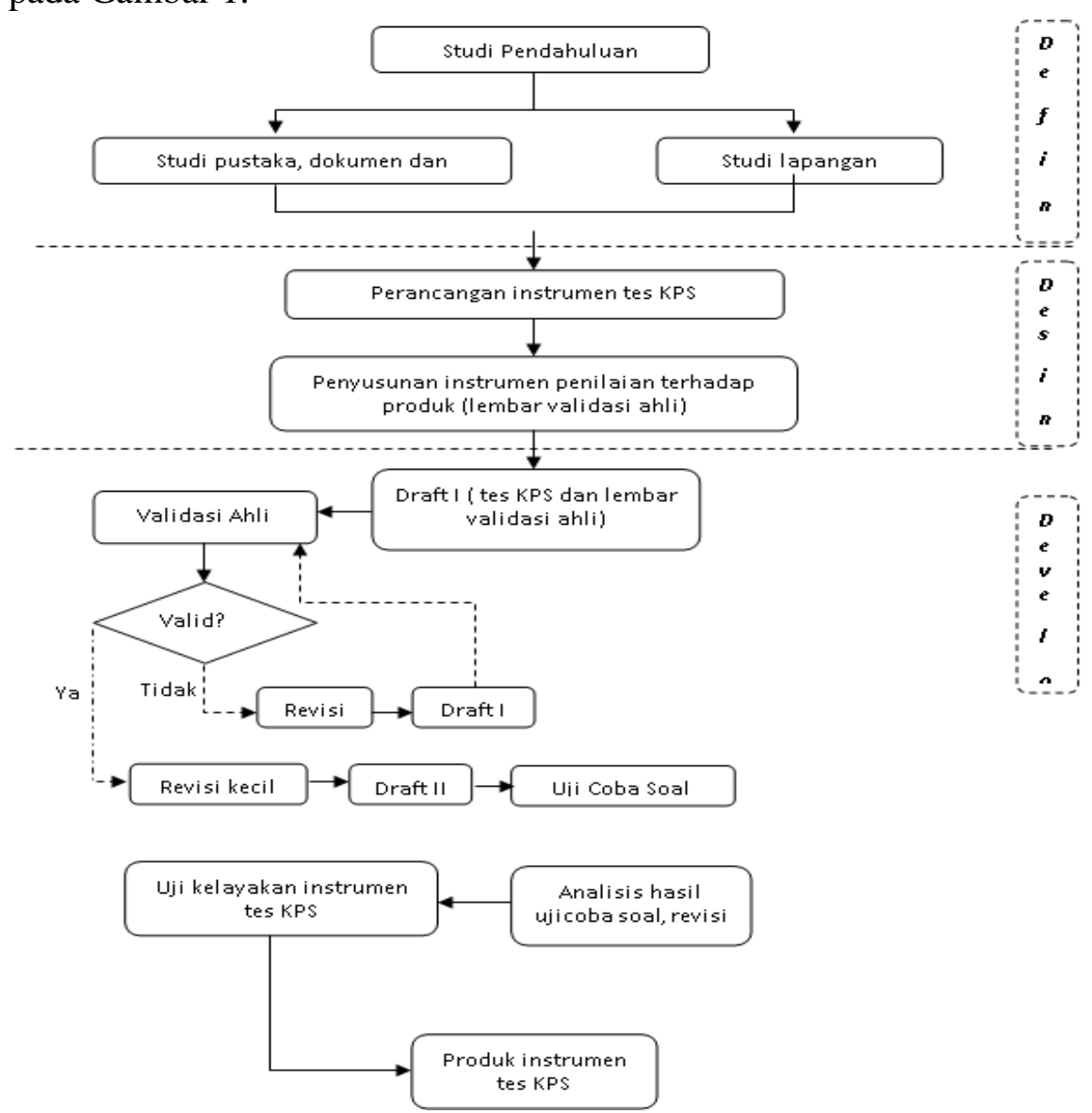

\section{Gambar 1 Bagan Rancangan Penelitian Pengembangan Instrumen Tes KPS}

Data penelitian diperoleh menggunakan teknik komunikasi tidak langsung, komunikasi langsung, dan tes. Pengumpulan data dilakukan pada tahap studi lapangan dan pada tahap uji coba terbatas (tanggapan produk). Pengumpulan data pada studi lapangan dilakukan melalui wawancara terhadap dua orang guru mata pelajaran fisika dan penyebaran angket ke 20 siswa SMP Negeri di Kecamatan Sungai Kakap. Pengumpulan data pada tahap uji coba lapangan awal (tanggapan produk) dilakukan dengan memberikan angket dan draf produk hasil validasi ahli 
kepada 4 orang dosen dan 2 orang guru untuk mengetahui tanggapan terhadap instrumen tes KPS yang telah dikembangkan dan pengujian tes KPS kepada siswa untuk mengetahui tingkat validitas, reliabilitas, daya pembeda, dan kesukaran soal.

Pengujian kelayakan produk instrumen tes KPS dilakukan oleh tiga pakar, yaitu 2 orang dosen pendidikan fisika dan 1 orang guru fisika SMA. Pertimbangan pakar dilakukan untuk menelaah kesesuaian butir soal dengan cakupan materi ajar serta indikator KPS yang diukur. Instrumen tes KPS dianggap layak untuk digunakan apabila skor penilaian lebih besar dari 62,5\% dengan kriteria baik (Sudijono, 2017). Apabila skor hasil penilaian masih lebih kecil atau sama dengan $62,5 \%$, maka produk perlu direvisi kembali. Adapun tabel kriteria penilaian pakar disajikan pada Tabel 1 .

Tabel 1 Kriteria Penilaian oleh Pakar

\begin{tabular}{cc}
\hline Rentang Persentase & Kriteria \\
\hline $81,25 \%<$ skor $\leq 100 \%$ & Sangat Baik \\
$62,50 \%<$ skor $\leq 81,25 \%$ & Baik \\
$43,75 \%<$ skor $\leq 62,50 \%$ & Cukup Baik \\
$25,00 \%<$ skor $\leq 43,75 \%$ & Tidak Baik \\
\hline
\end{tabular}

Uji coba lapangan dilakukan untuk melihat reliabilitas, daya pembeda, dan tingkat kesukaran tiap butir item tes. Validitas butir soal digunakan rumus korelasi product moment (Persamaan 1).

$$
r_{x y}=\frac{N \Sigma X Y-(\Sigma X)(\Sigma Y)}{\sqrt{\left(N \Sigma X^{2}-(\Sigma X)^{2}\right)\left(N \Sigma Y^{2}-(\Sigma Y)^{2}\right)}}
$$

Dengan rxy adalah koefisien korelasi antar variabel $\mathrm{X}$ dan $\mathrm{Y}$; $\mathrm{X}$ adalah nilai siswa tiap butir soal; $\mathrm{Y}$ adalah total nilai siswa; dan $\mathrm{N}$ adalah banyaknya peserta tes. Setelah diperoleh nilai rxy hitung, hasilnya dibandingkan dengan $\mathrm{r}$ kritik product moment tabel pada taraf signifikansi $\alpha=5 \%$. Jika rxy $>$ rtabel, maka soal dikatakan valid (Sugiyono, 2009).

Reliabilitas tes dilakukan dengan metode internal konsistensi. Nunnaly (Surapranata, 2004) menyatakan bahwa reliabilitas tes didasarkan pada homogenitas atau korelasi antara skor jawaban pada setiap butir tes. Karena hasil uji telaah pedoman tes oleh tim ahli memberikan tingkat skor skala likert, maka 
reliabilitas tes diagnostik diukur dengan menggunakan persamaan alpha cronbach (Persamaan 2).

$$
r_{11}=\frac{k z}{\{k-1\}}\left(1-\frac{\sum s_{1}^{2}}{s_{R}^{2}}\right)
$$

Dengan $\mathrm{r}_{11}$ adalah koefisien reliabilitas tes; $\mathrm{k}$ adalah jumlah soal; $\mathrm{Si}^{2}$ adalah jumlah varian dari skor soal; dan $\mathrm{St}^{2}$ adalah jumlah varian dari skor total. Untuk menentukan kategori dari koefisien reliabilitas tes digunakan kriteria terlihat pada Tabel 2.

Tabel 2 Interpretasi Nilai Reliabilitas Tes

\begin{tabular}{cc}
\hline Rentang Persentase & Kriteria \\
\hline $0,00 \leq \mathrm{r}_{11}<0,20$ & Sangat Rendah \\
$0,20 \leq \mathrm{r}_{11}<0,40$ & Rendah \\
$0,40 \leq \mathrm{r}_{11}<0,60$ & Sedang \\
$0,60 \leq \mathrm{r}_{11}<0,80$ & Kuat \\
$0,80 \leq \mathrm{r}_{11}<1,00$ & Sangat Kuat \\
\hline
\end{tabular}

Analisis tingkat kesukaran item tes dilakukan dengan cara menghitung indeks kesukaran menggunakan Persamaan 3.

$$
T K=\frac{B_{a}+B_{b}}{W_{a}+\mathbb{M}_{b}} x 100 \%
$$

Dengan TK adalah difficulty level (indeks kesukaran). Rentang indeks kesukaran adalah 0,00 sampai 1,00. Butir soal dengan indeks kesukaran 0,90 merupakan butir soal yang sangat mudah dan tidak tepat digunakan sebagai instrumen uji. Sedangkan butir soal dengan indeks kesukaran 0,20 merupakan butir soal yang sangat sulit dan perlu ditelaah lebih lanjut apa yang menjadi penyebab soal sukar, apakah butir soal sukar karena tata bahasa soal atau bermasalah pada konten (Boopathiraj dan Chellamani, 2013).

Analisis daya pembeda item soal dilakukan dengan cara menghitung koefisien daya pembeda menggunakan Persamaan 4.

$$
D P=\frac{2\left(B_{A}-B_{B}\right)}{W} x 100 \%
$$

Dengan DP adalah koefisien daya pembeda; BA adalah banyaknya peserta kelompok atas yang menjawab pertanyaan dengan benar; BB adalah banyaknya peserta kelompok bawah yang menjawab pertanyaan dengan benar; dan $\mathrm{N}$ adalah jumlah siswa yang mengerjakan tes. Nilai daya pembeda berkisar antara $-1,00$ 
hingga $+1,00$. Butir soal dikatakan baik dan dapat digunakan sebagai instrumen penilaian apabila memiliki indeks saya pembeda lebih dari 0,20, sedangkan butir soal yang memiliki daya pembeda negatif tidak dapat digunakan sebagai instrumen penilaian (Boopathiraj dan Chellamani, 2013).

\section{HASIL DAN PEMBAHASAN}

Instrumen KPS yang dikembangkan berbentuk pilihan ganda dan essay. Aspek keterampilan proses yang terukur dari instrumen penilaian KPS yaitu mengamati, memprediksi, mengukur, mengklasifikasikan, mengomunikasikan, dan menyimpulkan (Tabel 3, Tabel 4, dan Tabel 5).

Tabel 3 Sebaran Soal Tes KPS Berdasarkan Aspek KPS Materi Optika

\begin{tabular}{lcc}
\hline \multirow{2}{*}{ Indikator KPS } & \multicolumn{2}{c}{ Nomor Soal } \\
\cline { 2 - 3 } & Pilihan Ganda & Essay \\
\hline Mengamati & 1,2 & 13,14 \\
Memprediksi & 3,4 & 15,16 \\
Mengukur & 11,12 & 23,24 \\
Mengklasifikasikan & 9,10 & 21,22 \\
Mengomunikasikan & 7,8 & 19,20 \\
Menyimpulkan & 5,6 & 17,18 \\
\hline
\end{tabular}

Tabel 4 Sebaran Soal Tes KPS Berdasarkan Aspek KPS Materi Tekanan

\begin{tabular}{lcc}
\hline \multirow{2}{*}{ Indikator KPS } & \multicolumn{2}{c}{ Nomor Soal } \\
\cline { 2 - 3 } & Pilihan Ganda & Essay \\
\hline Mengamati & $12,13,14,15$ & 20,21 \\
Memprediksi & $6,7,8$ & 24,25 \\
Mengklasifikasikan & $9,10,11$ & 22,23 \\
Mengomunikasikan & 4,5 & 18,19 \\
Menyimpulkan & $1,2,3$ & 16,17 \\
\hline
\end{tabular}

Tabel 5 Sebaran Soal Tes KPS Berdasarkan Aspek KPS Materi Getaran dan Gelombang

\begin{tabular}{lcc}
\hline \multirow{2}{*}{ Indikator KPS } & \multicolumn{2}{c}{ Nomor Soal } \\
\cline { 2 - 3 } & Pilihan Ganda & Essay \\
\hline Mengamati & $1,2,3$ & 19,20 \\
Memprediksi & $4,5,6$ & 21,22 \\
Mengukur & $16,17,18$ & 29,30 \\
Mengklasifikasikan & $13,14,15$ & 27,28 \\
Mengomunikasikan & $10,11,12$ & 25,26 \\
Menyimpulkan & $7,8,9$ & 23,24 \\
\hline
\end{tabular}


Tabel 3, Tabel 4, dan Tabel 5 menunjukkan sebaran soal tiap aspek KPS. Aspek yang terukur dari instrumen penilaian KPS yang dikembangkan pada materi optika, getaran, dan gelombang terdiri dari mengamati, memprediksi, mengukur, mengklasifikasikan, mengomunikasikan, dan menyimpulkan. Sedangkan instrumen penilaian KPS materi tekanan hanya terdiri dari lima aspek KPS, yaitu mengamati, memprediksi, mengklasifikasikan, mengomunikasikan, dan menyimpulkan. Setiap aspek KPS dibuat lebih dari satu soal dengan tujuan agar soal yang dibuat lebih bervariasi untuk tiap aspek KPS.

Analisis uji validitas (kelayakan) instrumen KPS menurut pakar (ahli) diperoleh rata-rata persentase skor dari ketiga ahli sebesar 85,56 dengan kategori sangat baik untuk instrumen soal KPS materi optika; sebesar 78,43 dengan kategori baik untuk instrumen soal KPS materi tekanan; dan instrumen soal KPS materi getaran gelombang sebesar 79,04 dengan kategori baik. Penilaian dari pakar (ahli) tersebut, menunjukkan bahwa instrumen tes KPS yang dibuat dianggap layak dari segi konstruk, materi, dan bahasa. Menurut Santyasa (2014), validitas isi penting untuk tes hasil belajar dikarenakan suatu skor kurang bahkan tidak mencerminkan hasil belajar apabila instrumen tidak mampu mengukur secara komprehensif apa yang telah dipelajari oleh siswa. Validasi juga penting guna kesesuaian instrumen dengan kompetensi capaian pembelajaran, isi materi yang akurat, dan materi yang layak dari segi kemuktahiran (Wedyawati dan Lisa, 2018).

Setelah dinyatakan layak oleh ahli, tes kemudian diujilapangankan kepada siswa yang telah mempelajari materi yang diujikan yaitu siswa kelas IX SMP. Hasil analisis uji coba lapangan berupa validitas, daya pembeda, tingkat kesukaran, dan reliabilitas. Berdasarkan analisis validitas soal KPS diperoleh soal yang valid dan tidak valid (Tabel 6, Tabel 7, dan Tabel 8). Soal yang memiliki kriteria tidak valid dibuang dan tidak digunakan dikarenakan soal tersebut belum mampu mengukur apa yang akan diukur.

Hasil tingkat kesukaran soal KPS yang dikembangkan juga bervariasi yaitu soal kategori sukar, sedang, dan mudah. Selain itu, kriteria daya pembeda soal diperoleh soal dengan daya pembeda sangat baik; soal dengan kriteria daya 
pembeda baik; soal dengan kriteria daya pembeda cukup; dan soal dengan kriteria daya pembeda jelek. Untuk soal yang memiliki kriteria daya pembeda jelek, soal tidak dibuang namun diperbaiki. Hal tersebut sesuai dengan pendapat Santyasa (2014), bahwa indeks daya beda butir soal tidak selalu menjadi suatu ukuran kualitas butir soal artinya rendahnya indeks daya pembeda bukan ukuran rendahnya kualitas butir soal. Selain validitas, tingkat kesukaran, dan daya beda, suatu tes juga perlu dilihat keajegan atau reliabilitas. Hasil analisis reliabilitas soal KPS nenunjukkan bahwa kriteria indeks reliabilitas soal berada pada rentang sedang dan baik. Hal tersebut menunjukkan bahwa soal KPS materi optika yang dibuat memiliki konsistensi yang baik, artinya suatu tes mampu memberikan hasil yang sama untuk subjek yang sama pada waktu yang berbeda (Feyzioglu, dkk., 2012).

Tabel 6 Hasil Uji Validitas Tes KPS Materi Optika

\begin{tabular}{|c|c|c|c|c|c|c|c|c|c|}
\hline \multirow{2}{*}{$\begin{array}{c}\text { Nomor } \\
\text { Soal }\end{array}$} & \multicolumn{3}{|c|}{ Validitas } & \multicolumn{2}{|c|}{ Daya Pembeda } & \multicolumn{2}{|c|}{$\begin{array}{c}\text { Tingkat } \\
\text { Kesukaran }\end{array}$} & \multirow{2}{*}{ Keputusan } & \multirow{2}{*}{ Reliabilitas } \\
\hline & $\mathbf{r}_{\text {hitung }}$ & $\mathbf{r}_{\text {tabel }}$ & Kriteria & $\begin{array}{c}\text { Nilai } \\
\text { Indeks }\end{array}$ & Kriteria & $\begin{array}{c}\text { Nilai } \\
\text { Indeks }\end{array}$ & Kriteria & & \\
\hline 1 & 0,535 & 0,423 & Valid & 0,51 & Baik & 0,23 & Sukar & Diterima & \multirow{11}{*}{$\begin{array}{c}0,87 \\
\text { (Sangat } \\
\text { Kuat) }\end{array}$} \\
\hline 2 & 0,462 & 0,423 & Valid & 0,51 & Baik & 0,14 & Sukar & Diterima & \\
\hline 3 & 0,465 & 0,423 & Valid & 1,00 & Sangat Baik & 0,45 & Sedang & Diterima & \\
\hline 4 & 0,157 & 0,423 & Tidak Valid & 0,17 & Jelek & 0,32 & Sedang & Dibuang & \\
\hline 5 & 0,054 & 0,423 & Tidak Valid & 0,17 & Jelek & 0,32 & Sedang & Dibuang & \\
\hline 6 & 0,467 & 0,423 & Valid & 0,51 & Baik & 0,32 & Sedang & Diterima & \\
\hline 7 & 0,136 & 0,423 & Tidak Valid & 0,17 & Jelek & 0,41 & Sedang & Dibuang & \\
\hline 8 & 0,550 & 0,423 & Valid & 1,00 & Sangat Baik & 0,27 & Sukar & Diterima & \\
\hline 9 & 0,429 & 0,423 & Valid & 0,51 & Baik & 0,41 & Sedang & Diterima & \\
\hline 10 & 0,465 & 0,423 & Valid & 0,34 & Cukup & 0,45 & Sedang & Diterima & \\
\hline 11 & 0,429 & 0423 & Valid & 0,51 & Baik & 0,41 & Sedang & Diterima & \\
\hline 12 & $-0,011$ & 0,423 & Tidak Valid & 0,17 & Jelek & 0,41 & Sedang & Dibuang & \multirow{13}{*}{$\begin{array}{c}0,60 \\
\text { (Sedang) }\end{array}$} \\
\hline 13 & 0,665 & 0,423 & Valid & 0,58 & Baik & 0,68 & Sedang & Diterima & \\
\hline 14 & 0,432 & 0,423 & Valid & 0,49 & Baik & 0,64 & Sedang & Diterima & \\
\hline 15 & 0,664 & 0,423 & Valid & 0,82 & Sangat Baik & 0,59 & Sedang & Diterima & \\
\hline 16 & 0,312 & 0,423 & Tidak Valid & 0,60 & Baik & 0,77 & Mudah & Dibuang & \\
\hline 17 & 0,560 & 0,423 & Valid & 0,44 & Baik & 0,68 & Sedang & Diterima & \\
\hline 18 & 0,236 & 0,423 & Tidak Valid & 0,10 & Jelek & 0,64 & Sedang & Dibuang & \\
\hline 19 & 0,253 & 0,423 & Tidak Valid & 0,22 & Jelek & 0,59 & Sedang & Dibuang & \\
\hline 20 & 0,533 & 0,423 & Valid & 0,49 & Baik & 0,68 & Sedang & Diterima & \\
\hline 21 & 0,547 & 0,423 & Valid & 0,56 & Baik & 0,45 & Sedang & Diterima & \\
\hline 22 & 0,375 & 0,423 & Tidak Valid & 0,40 & Cukup & 0,68 & Sedang & Dibuang & \\
\hline 23 & 0,505 & 0,423 & Valid & 0,66 & Baik & 0,82 & Mudah & Diterima & \\
\hline 24 & 0,477 & 0,423 & Valid & 0,28 & Jelek & 0,73 & Mudah & Diperbaiki & \\
\hline
\end{tabular}

Berdasarkan Tabel 6, diketahui bahwa dari 24 soal KPS materi optika sebanyak 8 soal dengan keputusan dibuang yaitu tiga soal berbentuk pilihan ganda 
dan lima soal berbentuk essay serta satu soal diperbaiki. Soal yang dibuang yaitu soal dengan kategori tidak valid dan indeks daya pembeda jelek. Sedangkan soal dengan kriteria valid namun daya pembeda jelek tidak dibuang melainkan diperbaiki redaksinya.

Tabel 7 Hasil Uji Validitas Tes KPS Materi Tekanan

\begin{tabular}{|c|c|c|c|c|c|c|c|c|c|}
\hline \multirow{2}{*}{$\begin{array}{c}\text { Nomor } \\
\text { Soal }\end{array}$} & \multicolumn{3}{|c|}{ Validitas } & \multicolumn{2}{|c|}{ Daya Pembeda } & \multicolumn{2}{|c|}{$\begin{array}{c}\text { Tingkat } \\
\text { Kesukaran }\end{array}$} & \multirow{2}{*}{ Keputusan } & \multirow{2}{*}{ Reliabilitas } \\
\hline & $\mathbf{r}_{\text {hitung }}$ & $\mathbf{r}_{\text {tabel }}$ & Kriteria & $\begin{array}{c}\text { Nilai } \\
\text { Indeks }\end{array}$ & Kriteria & $\begin{array}{c}\text { Nilai } \\
\text { Indeks }\end{array}$ & Kriteria & & \\
\hline 1 & 0,160 & 0,444 & Tidak Valid & 0,00 & Jelek & 0,60 & Sedang & Dibuang & \multirow{15}{*}{$\begin{array}{c}0,71 \\
\text { (Kategori } \\
\text { Kuat) }\end{array}$} \\
\hline 2 & 1,937 & 0,444 & Valid & 0,50 & Baik & 0,65 & Sedang & Diterima & \\
\hline 3 & 1,596 & 0,444 & Valid & 0,50 & Baik & 0,75 & Mudah & Diterima & \\
\hline 4 & 0,041 & 0,444 & Tidak Valid & 0,00 & Jelek & 0,60 & Sedang & Dibuang & \\
\hline 5 & 0,671 & 0,444 & Valid & 0,30 & Cukup & 0,45 & Sedang & Diterima & \\
\hline 6 & 0,529 & 0,444 & Valid & 0,60 & Baik & 0,60 & Sedang & Diterima & \\
\hline 7 & 0,698 & 0,444 & Valid & 0,30 & Cukup & 0,55 & Sedang & Diterima & \\
\hline 8 & 0,273 & 0,444 & Valid & 0,20 & Jelek & 0,30 & Sukar & Diperbaiki & \\
\hline 9 & 0,444 & 0,444 & Valid & 0,60 & Baik & 0,60 & Sedang & Diterima & \\
\hline 10 & 0,277 & 0,444 & Tidak Valid & 0,30 & Cukup & 0,35 & Sedang & Dibuang & \\
\hline 11 & 0,453 & 0,444 & Valid & 0,60 & Baik & 0,50 & Sedang & Diterima & \\
\hline 12 & 0,632 & 0,444 & Valid & 0,40 & Cukup & 0,70 & Sedang & Diterima & \\
\hline 13 & 0,578 & 0,444 & Valid & 0,30 & Cukup & 0,85 & Mudah & Diterima & \\
\hline 14 & 0,578 & 0,444 & Valid & 0,50 & Baik & 0,65 & Sedang & Diterima & \\
\hline 15 & 0,470 & 0,444 & Valid & 0,30 & Cukup & 0,75 & Mudah & Diterima & \\
\hline 16 & 0,386 & 0,444 & Tidak Valid & 0,20 & Jelek & 0,60 & Sedang & Dibuang & \multirow{10}{*}{$\begin{array}{c}0,41 \\
\text { (Kategori } \\
\text { Sedang) }\end{array}$} \\
\hline 17 & 0,649 & 0,444 & Valid & 0,70 & Baik & 0,45 & Sedang & Diterima & \\
\hline 18 & 0,453 & 0,444 & Valid & 0,10 & Jelek & 0,95 & Mudah & Diperbaiki & \\
\hline 19 & 0,626 & 0,444 & Valid & 0,30 & Cukup & 0,35 & Sedang & Diterima & \\
\hline 20 & 0,577 & 0,444 & Valid & 0,30 & Cukup & 0,85 & Sedang & Diterima & \\
\hline 21 & 0,453 & 0,444 & Valid & 0,10 & Jelek & 0,95 & Sedang & Diperbaiki & \\
\hline 22 & 0,396 & 0,444 & Tidak Valid & 0,13 & Jelek & 0,90 & Sedang & Dibuang & \\
\hline 23 & 0,106 & 0,444 & Tidak Valid & 0,06 & Jelek & 0,93 & Sedang & Dibuang & \\
\hline 24 & 0,066 & 0,444 & Tidak Valid & 0,02 & Jelek & 0,38 & Sedang & Dibuang & \\
\hline 25 & 0,528 & 0,444 & Valid & 0,27 & Jelek & 0,23 & Sukar & Diterima & \\
\hline
\end{tabular}

Tabel 7, menunjukkan bahwa tingkat reliabilitas soal sangat kuat untuk soal berbentuk pilihan ganda dan tingat reliabilitas sedang untuk soal berbentuk essay. Namun jika dilihat uji validitas empirik, terdapat tujuh soal yang dinyatakan tidak valid dan memiliki tingkat daya pembeda jelek. Untuk soal yang demikian, diputuskan dibuang dan tidak digunakan, yaitu soal nomor 1, 4, 10, 16, 22, 23, dan 24. Sedangkan untuk soal dengan kriteria valid namun daya pembeda jelek, maka soal diperbaiki dari segi redaksinya, yaitu soal nomor 8, 18, dan 21 . 
Tabel 8 Hasil Uji Validitas Tes KPS Materi Getaran dan Gelombang

\begin{tabular}{|c|c|c|c|c|c|c|c|c|c|}
\hline \multirow[b]{2}{*}{$\begin{array}{c}\text { Nomor } \\
\text { Soal }\end{array}$} & \multicolumn{3}{|c|}{ Validitas } & \multicolumn{2}{|c|}{ Daya Pembeda } & \multicolumn{2}{|c|}{ Tingkat Kesukaran } & \multirow[b]{2}{*}{ Keputusan } & \multirow[b]{2}{*}{ Reliabilitas } \\
\hline & $\mathbf{r}_{\text {hitung }}$ & $\mathbf{r}_{\text {tabel }}$ & Kriteria & $\begin{array}{c}\text { Nilai } \\
\text { Indeks }\end{array}$ & Kriteria & $\begin{array}{c}\text { Nilai } \\
\text { Indeks }\end{array}$ & Kriteria & & \\
\hline 1 & 0,90 & 0.576 & Valid & 0.17 & Jelek & 0.92 & Mudah & Diperbaiki & \multirow{18}{*}{$\begin{array}{c}0,83 \\
\text { (Kategori } \\
\text { Sangat Kuat) }\end{array}$} \\
\hline 2 & $-0,21$ & 0.576 & Tidak Valid & 0.17 & Jelek & 0.42 & Sedang & Dibuang & \\
\hline 3 & 0,90 & 0.576 & Valid & 0.17 & Jelek & 0.92 & Mudah & Diperbaiki & \\
\hline 4 & $-0,17$ & 0.576 & Tidak Valid & 0.00 & Jelek & 0.67 & Sedang & Dibuang & \\
\hline 5 & 0,67 & 0.576 & Valid & 0.50 & Baik & 0.42 & Sedang & Diterima & \\
\hline 6 & 0,58 & 0.576 & Valid & 0.50 & Baik & 0.75 & Mudah & Diterima & \\
\hline 7 & 0,31 & 0.576 & Tidak Valid & 0.33 & Cukup & 0.17 & Sukar & Dibuang & \\
\hline 8 & 0,90 & 0.576 & Valid & 0.17 & Jelek & 0.92 & Mudah & Diperbaiki & \\
\hline 9 & $-0,10$ & 0.576 & Tidak Valid & -0.17 & Jelek & 0.92 & Mudah & Dibuang & \\
\hline 10 & 0,58 & 0.576 & Valid & 0.33 & Cukup & 0.50 & Sedang & Diterima & \\
\hline 11 & 0,01 & 0.576 & Tidak Valid & -0.17 & Jelek & 0.92 & Mudah & Dibuang & \\
\hline 12 & 0,75 & 0.576 & Valid & 0.33 & Cukup & 0.83 & Mudah & Diterima & \\
\hline 13 & 0,90 & 0.576 & Valid & 0.17 & Jelek & 0.92 & Mudah & Diperbaiki & \\
\hline 14 & 0,67 & 0.576 & Valid & 0.00 & Jelek & 0.83 & Mudah & Diperbaiki & \\
\hline 15 & $-0,10$ & 0.576 & Tidak Valid & -0.17 & Jelek & 0.92 & Mudah & Dibuang & \\
\hline 16 & 0,75 & 0.576 & Valid & 0.33 & Cukup & 0.83 & Mudah & Diterima & \\
\hline 17 & 0,09 & 0.576 & Tidak Valid & 0.17 & Jelek & 0.75 & Mudah & Dibuang & \\
\hline 18 & 0,67 & 0.576 & Valid & 0.33 & Cukup & 0.83 & Mudah & Diterima & \\
\hline 19 & 0,72 & 0,576 & Valid & 0,00 & Jelek & 0,78 & Mudah & Diperbaiki & \multirow{12}{*}{$\begin{array}{c}0,41 \\
\text { (Kategori } \\
\text { Sedang) }\end{array}$} \\
\hline 20 & 0,72 & 0,576 & Valid & 0,07 & Jelek & 0,97 & Mudah & Diperbaiki & \\
\hline 21 & $-0,01$ & 0,576 & Tidak Valid & $-0,07$ & Jelek & 0,86 & Mudah & Dibuang & \\
\hline 22 & 0,58 & 0,576 & Valid & 0,33 & Cukup & 0,86 & Mudah & Diterima & \\
\hline 23 & 0,65 & 0,576 & Valid & 0,45 & Baik & 0,52 & Sedang & Diterima & \\
\hline 24 & 0,20 & 0,576 & Tidak Valid & 0,15 & Jelek & 0,44 & Sedang & Dibuang & \\
\hline 25 & $-0,33$ & 0,576 & Tidak Valid & $-0,33$ & Jelek & 0,58 & Sedang & Dibuang & \\
\hline 26 & 0,76 & 0,576 & Valid & 0,47 & Baik & 0,42 & Sedang & Diterima & \\
\hline 27 & 0,65 & 0,576 & Valid & 0,00 & Jelek & 0,89 & Mudah & Diperbaiki & \\
\hline 28 & $-0,42$ & 0,576 & Tidak Valid & 0,00 & Jelek & 0,50 & Sedang & Dibuang & \\
\hline 29 & $-6,57$ & 0,576 & Tidak Valid & 0,60 & Baik & 0,58 & Sedang & Dibuang & \\
\hline 30 & 0,66 & 0,576 & Valid & 0,50 & Baik & 0,38 & Sedang & Diterima & \\
\hline
\end{tabular}

Tabel 8 menunjukkan hasil keputusan soal KPS yang dikembangkan untuk materi getaran dan gelombang. Hasil analisis uji coba diperoleh dari 30 soal yang dikembangkan. Sebanyak 11 soal dengan keputusan dibuang dan 8 soal diperbaiki. Soal yang dibuang yaitu soal dengan kategori tidak valid sedangkan soal yang diperbaiki dengan kategori valid namun kategori daya pembeda jelek.

\section{SIMPULAN}

Berdasarkan hasil analisis butir soal terhadap kualitas butir soal menunjukkan bahwa soal tes yang dikembangkan dapat mengukur keterampilan proses sains siswa materi optika, tekanan, dan getaran gelombang pada aspek mengamati, memprediksi, mengukur, mengklasifikasikan, mengomunikasikan, 
dan menyimpulkan. Kualitas butir soal diperoleh dari analisis telaah ahli dan analisi uji coba yang terdiri dari validitas, reliabilitas, tingkat kesukaran, dan daya pembeda soal, maka disimpulkan: (1) Validitas atau kelayakan instrumen KPS pada materi optika, tekanan, dan getaran gelombang yang dikembangkan adalah valid dan layak digunakan. Hal tersebut terlihat dari hasil penilaian ahli dari aspek konstruk, materi, dan isi memiliki kategori baik; (2) Validitas butir soal dari instrumen penilaian KPS pada materi optika, tekanan, dan getaran gelombang yang dikembangkan dengan kriteria valid yang berarti soal sudah sahih dalam mengukur kemampuan siswa sesuai indikator; (3) Reliabilitas soal dari instrumen KPS sangat kuat untuk soal pilihan ganda materi optika dan getaran gelombang, reliabilitas kuat untuk soal materi tekanan dan reliabilitas sedang untuk soal essay materi optika, tekanan, dan getaran gelombang. Hal tersebut menunjukkan soal dapat menggambarkan kemampuan siswa pada aspek keterampilan proses sains; dan (4) Soal-soal yang dikembangkan dalam instrumen penilaian KPS pada materi optika, tekanan, dan getaran gelombang didominasi soal dengan kategori sedang.

\section{DAFTAR PUSTAKA}

Apriyani, A. 2017. Pengembangan Instrumen Asesmen Kognitif Berbasis Ketrampilan Proses Sains pada Materi Larutan Elektrolit dan Non Elektrolit. Tersedia di http://repository.lppm.unila.ac.id/5749/1/13505-29271-2PB.pdf. Diakses tanggal 15 Maret 2018.

Arifin, R. A., Supriana, E., \& Munfaridah, N. 2016. Pengembangan Multimedia Interaktif untuk Kelas XI MIPA Pokok Bahasan Dinamika Rotasi. Jurnal Riset Pendidikan Fisika, 1(1): 17-21.

Boopathiraj, C. \& Chellamani, K. 2013. Analysis of Test Items on Difficulty Level and Discrimination Index in the Test for Research Education. International Journal of Social Science \& Interdisciplinary Research, 2: 189-193.

Feyzioglu, B., Demirdag, B., Akyildiz, M., \& Altun, E. 2012. Developing a Science Process Skills Test for Secondary Students: Validity and Reliability Study. Educational Sciences: Theory and Practice, 12(3): 1899-1906.

Feyzioglu, B. 2009. An Investigation of the Relationship Between Science Process Skills with Efficient Laboratory Use and Science Achievement in Chemistry Education. Journal of Turkish Science Education, 6(3): 114-132. Jihad, A. \& Haris. 2012. Evaluasi Pembelajaran. Multi Pressindo: Yogyakarta. 
Okaviani, E., Fadiawati, N., \& Kadaritna, N. 2015. Pengembangan Instrumen Asesmen Berbasis Ketrampilan Proses Sains pada Materi Hukum-Hukum Dasar Kimia. Jurnal Pendidikan dan Pembelajaran Kimia, 4(1): 324-338.

Permendikbud. 2013. Peraturan Menteri Pendidikan dan Kebudayaan Republik Indonesia Nomor 66 Tahun 2013. Tersedia di https://luk.staff.ugm.ac.id/atur/bsnp/Permendikbud66-2013SPenilaian.pdf. Diakses tanggal 20 Maret 2019.

Rustaman, N. 2005. Strategi Belajar Mengajar Biologi. Malang: Universitas Negeri Malang.

Santyasa, I. W. 2014. Asesmen dan Evaluasi Pembelajaran Fisika. Yogyakarta: Graha Ilmu.

Sugiyono. 2009. Metode Penelitian Kuantitatif, Kualitatif dan $R \& D$. Bandung: Alfabeta.

Surapranata. 2004. Analisis, Validitas, Reliabilitas, dan Interpretasi Hasil Tes. Bandung: Remaja Rosdakarya.

Thiagarajan, S., Doroty, S. S., \& Melvyn, I. S. 1974. Instructional Development for Training Teachers of Exceptional Children. Source Book. Bloominton: Center for Innovation on Theaching the Handicapped.

Wati, S. A., Fadiawati, N., \& Tania, L. 2015. Pengembangan Instrumen Asesmen Berbasis Ketrampilan Proses Sains pada Bahasan Klarifikasi Materi. Jurnal Pendidikan dan Pembelajaran Kimia, 4(2): 693-707.

Wedyawati, N. \& Lisa, Y. 2018. Kelayakan Buku Ajar Mata Kuliah Pembelajaran IPA SD bagi Mahasisa PGSD. Edukasi: Jurnal Pendidikan, 16(2): 155-168.

Zamista, A. A. \& Kaniawati, I. 2015. Pengembangan Tes Keterampilan Proses Sains Materi Fluida Statis Kelas X SMA/MA. Prosiding Seminar Nasional Fisika, Jakarta: Hal. 5-10. 